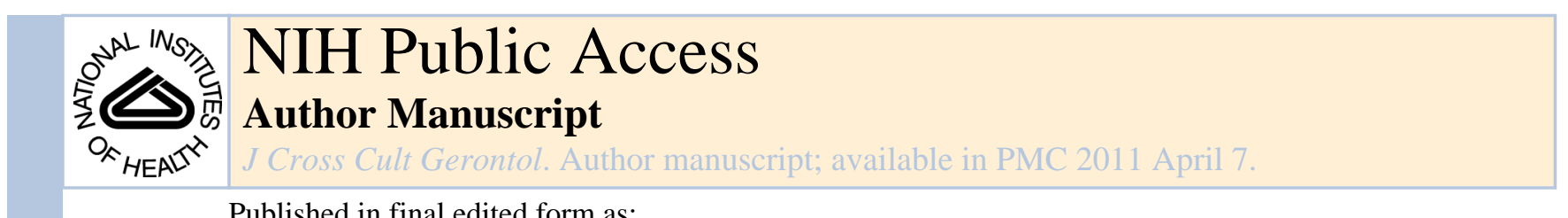

Published in final edited form as:

J Cross Cult Gerontol. 2010 December ; 25(4): 343-354. doi:10.1007/s10823-010-9119-5.

\title{
Comorbidity among Older American Indians: The Native Elder Care Study
}

\author{
R. Turner Goins and \\ Department of Community Medicine, Center on Aging, Robert C. Byrd Health Sciences Center, \\ West Virginia University, P.O. Box 9127, Morgantown, WV 26506, USA \\ Courtney S. Pilkerton \\ Dual MD/PhD Program, Robert C. Byrd Health Sciences Center, West Virginia University, P.O. \\ Box 9127, Morgantown, WV 26506, USA
}

R. Turner Goins: rgoins@hsc.wvu.edu

\begin{abstract}
Comorbidity is a growing challenge and the older adult population is most at risk of developing comorbid conditions. Comorbidity is associated with increased risk of mortality, increased hospitalizations, increased doctor visits, increased prescription medications, nursing home placement, poorer mental health, and physical disability. American Indians experience some of the highest rates of chronic conditions, but to date there have been only two published studies on the subject of comorbidity in this population. With a community-based sample of 505 American Indians aged 55 years or older, this study identified the most prevalent chronic conditions, described comorbidity, and identified socio-demographic, functional limitations, and psychosocial correlates of comorbidity. Results indicated that older American Indians experience higher rates of hypertension, diabetes, back pain, and vision loss compared to national statistics of older adults. Two-thirds of the sample experienced some degree of comorbidity according to the scale used. Older age, poorer physical functioning, more depressive symptomatology, and lower personal mastery were all correlates of higher comorbidity scores. Despite medical advances increasing life expectancy, morbidity and mortality statistics suggest that the health of older American Indians lags behind the majority population. These findings highlight the importance of supporting chronic care and management services for the older American Indian population.
\end{abstract}

\section{Keywords}

American Indian; Chronic conditions; Comorbidity

\section{Introduction}

Comorbidity, the presence of two or more chronic conditions in an individual, is a growing challenge for the United States health care system with the older adult population being most at risk of developing comorbid conditions. It is particular important to understand the burden of comorbidity in American Indians who are a race/ethnic group who experience significant health disparities (Indian Health Service 2002). Although over 4.2 million American Indians live in the U.S. (U.S. Census Bureau 2002) and the number of American Indians aged 65 years or older is projected to increase $3 \frac{1}{2} 2$ fold between 2,010 and 2,050 
from 410,000 to 1,395,000 (U.S. Census Bureau 2008), we know virtually nothing about the aging process in this vulnerable population.

In 2000, 57 million Americans had multiple chronic conditions and by 2020 this number is expected to grow to 81 million (Wu and Green 2000). Forty-five percent of persons aged 65 to 79 years and $54 \%$ of those aged 80 years or older have three or more chronic conditions (Paez et al. 2009). The health care system is faced with the expense of caring for these individuals. Sixty-five percent of those with Medicare have two or more chronic conditions, but they represent 95\% of Medicare expenditures (Wolff et al. 2002). Medicare per beneficiary spending increases with age, but it increases more significantly with increasing number of comorbid conditions (Anderson 2002).

The presence of one chronic condition increases the likelihood of having other chronic conditions (Marengoni et al. 2009) and the presence of comorbid conditions is associated with a host of negative outcomes. Comorbidity is associated with increased risk of mortality (Incalzi et al. 1997), number of hospitalizations (Wolff et al. 2002), number of doctor visits (Starfield et al. 2005), number of prescription medications (Anderson 2002), risk of nursing home placement (Harboun et al. 2008; Smith et al. 2000), poorer mental health (Stewart et al. 1989), and physical disability (Fried et al. 2004; Guralnik et al. 1989; Rozzini et al. 2002; Stewart et al. 1989; Verbrugge et al. 1990; Verbrugge et al. 1991). Moreover, having certain pairs of chronic conditions produces additive and synergistic effects causing greater negative outcomes in functional status and well being than would be expected from the sum of the effects from each condition alone (Fried et al. 1999; Rozzini et al. 2002; Stewart et al. 1989; Verbrugge et al. 1990).

Few studies have addressed comorbidity in older minority populations. One study, looking at comorbidity in African American and White populations aged 25 years or older determined African Americans had a greater number of chronic conditions and based on scores determined by the Charlson Comorbidity Index had higher comorbidity scores than their White counterparts (McGee et al. 1996). Isolating those aged 65 years or older, McGee et al. (1996) and colleagues found the same results with the exception of African American males who had a slightly lower average comorbidity score than White males. In another study, comorbidity was examined based on five conditions (hypertension, cancer, diabetes, coronary artery disease, and cerebrovascular disease) in a sample of African American and White persons aged 65 years or older (Fillenbaum et al. 2000). This study found an increased risk of comorbidity for African Americans if they had diabetes, hypertension, or cerebrovascular disease; there was no racial differences seen for either cancer or coronary artery disease.

We know even less about comorbidity among older American Indians. To date, there have been two published studies on the subject (Chapleski et al. 1997; John et al. 2003).

Chapleski and colleagues with 1994 data from a sample of 309 community-dwelling American Indians aged 55 years or older examined patterns of morbidity and comorbidity. Morbidity was measured from self-report in response to whether a health care professional had told the respondent in the past 12 months if they had any of 21 chronic conditions. Comorbidity was measured with both a count of these conditions and the Charlson Comorbidity Index. Results indicated that $7 \%$ of the sample had none of the 21 conditions, $25 \%$ had between one to two conditions, and $68 \%$ had three or more conditions. Some of the most prevalent conditions were arthritis, hypertension, diabetes, hearing loss, and vision loss. Increased age was significantly associated with greater comorbidity per the Charlson Comorbidity Index although gender, education, and marital status were not. 
John and colleagues with data collected in the mid-1990s from a community-dwelling sample of 1,039 American Indians aged 60 years or older assessed the patterns of comorbidity. They measured comorbidity with self-report in response to whether a health care professional had told the respondent they had any of 11 chronic conditions. They found that $13 \%$ had none of the 11 conditions, $31 \%$ had between one to two conditions, and $57 \%$ had three or more conditions. Some of the most prevalent conditions were vision loss, arthritis, hearing loss, depression, hypertension, and diabetes. Examination of conditional counts revealed that stroke was associated with the highest number of other occurring conditions and arthritis had the lowest level of comorbidity. A comorbidity severity measure weighted the conditions based on the extent to which it gets in the way of daily activities and revealed that the average comorbidity score was 7.3 and that stroke was the condition that had the highest comorbidity severity score. Comorbid pairs were also examined and the most common comorbid pair was arthritis and vision problems. Lastly, these researchers conducted a cluster analysis of the diseases and found a four-cluster structure. The largest cluster consisted of six conditions including stroke, heart disease, diabetes, tuberculosis, urinary tract or bladder problems, and hypertension. The second largest cluster consisted of three condition including vision problems, hearing problems, and problems with teeth or gums. The third cluster consisted of depression and arthritis was the fourth cluster.

With only two published studies in this area with different analytic approaches, it is difficult to summarize what it known about comorbidity among older American Indians. We do know, however, that American Indians experience some of the highest rates of chronic conditions (Indian Health Service 2002). For example, diabetes, a chronic disease found to have a strong association with accompanying disability, is one of the most serious chronic health problems for American Indian elders. Nationally, more than one in five American Indian elders have diabetes (Denny et al. 2005), which is usually associated with an increase in other chronic health conditions (Howard et al. 1999; Sievers et al. 1999).

The National Institute on Aging Task Force on Comorbidity has called for a greater focus on comorbidity in geriatric care and research (Yancik et al. 2007). Understanding comorbidity for American Indian elders will yield valuable information that can inform efforts on reducing the health disparities currently faced by this population. Thus, the purpose of our study was to examine the most prevalent chronic conditions, describe comorbidity, and identify socio-demographic, functional limitations, and psychosocial correlates of comorbidity among a sample of older American Indians.

\section{Methods}

\section{Data source}

Data were collected as part of the Native Elder Care Study, a cross-sectional study of disability among older American Indians. Interviewer-administered questionnaires were conducted between July 2006 and August 2008 with members of federally-recognized tribe in the Southeast region of the U.S. To be included in the study, participants had to be an enrolled tribal member, reside in the tribe's service area, and be aged 55 years or older. We used a lower age criterion because American Indians appear to be experiencing expansion of morbidity (Hayward and Heron 1999), indicating that the chronological pace of aging among American Indians might exceed that of other racial groups.

Per tribal enrollment records, there were 1,430 potentially eligible participants based on age and residential location. This list was randomized in Microsoft Access and the names and contact information were distributed to interviewers. Equal numbers of respondents were sought for the age groups 55-64, 65-74, and 75 years or older until a sample of 500 was obtained. These persons were initially contacted by an interviewer via a telephone call or a 
home visit. The in-person interviews lasted between 60 and $90 \mathrm{~min}$. We did not interview persons who were institutionalized, and all study participants aged 65 years or older passed a dementia screening test (Inouye et al. 1998). Proxy interviews were not conducted. We assessed 633 persons for eligibility and 50 were determined as ineligible. Of these 50 individuals, we determined that three who lived outside the service area, 14 were in a nursing home, 19 were deceased, and 14 did not pass the dementia screen. Most interviews were conducted in the participant's home (87\%) and the remaining were conducted in a tribal building. Seventy-eight persons refused to participate, yielding an $87 \%$ response rate and a final sample size of 505. In relation to tribal roll information, our sample included 167 out of the 761 persons aged 55-64 years, 185 out of the 431 persons aged 65-74 years, and 153 persons out of the 238 persons aged 75 years or older. Propensity to decline participation increased with age, although this was not significant, and men were more likely to decline than women $(54 \%$ vs. $46 \%, p \leq 0.001)$. The tribe's Institutional Review Board, Tribal Council, and Elder Council approved the project. The West Virginia University Institutional Review Board approval was obtained. All study participants received a $\$ 20$ gift card.

\section{Measures}

Comorbidity scale-Comorbidity was our dependent variable for this study. The Native Elder Care Study used a survey-based comorbidity measure that has previously been used with community-dwelling older adults (Rigler et al. 2002) and we expanded the number of chronic conditions from its original 19 to 32 . The conditions included angina, congestive heart failure, heart attack, lung disease, arthritis, osteoporosis, broken bone, joint replacement, joint fusion, amputation, Parkinson's disease, stroke, depression/anxiety/ emotional problem, sleep problem, back pain, chronic pain syndrome, cancer, diabetes, glaucoma, cataracts, heart disease, high blood pressure, ulcer or stomach disease, kidney disease, liver disease, anemia or other blood disease, vision loss, hearing loss, skin disorders, epilepsy, multiple sclerosis, and urinary track disorders. The interviewer asked, "Since age 55 has a doctor told you that you had ...?" with response options of yes and no. If the respondent indicated "yes," the interviewer asked the follow up question, "How much does it limit your ability to do your daily activities?" with response options of none, a little bit, somewhat, or quite a bit (scored 0-3, respectively). If the respondent indicated "no," the interviewer asked the same initial question for the next condition for all 32 conditions. The comorbidity scale was a summary of the severity of the chronic conditions that can range from 0 to 96 with higher scores indicating greater comorbidity. A total of 446 respondents had complete data on the comorbidity scale.

Independent variables-We examined three categories of independent variables including socio-demographics, functional limitations, and psychosocial factors. The sociodemographics included age, gender, income, educational attainment, marital status, and living arrangements. We treated age as a continuous variable (range: 55-104 years). Annual household income was an ordinal variable using seven categories $(\leq \$ 9,999, \$ 10 \mathrm{~K}-\$ 14,999$, $\$ 15 \mathrm{~K}-\$ 19,999, \$ 20 \mathrm{~K}-\$ 24,999, \$ 25 \mathrm{~K}-\$ 34,999, \$ 35 \mathrm{~K}-\$ 49,999$, and $\geq \$ 50 \mathrm{~K})$.

Educational attainment was an ordinal variable measured using three categories ( $\leq 11$ years, high school graduate/General Educational Development, and some college or beyond). Marital status was a binary variable and indicated whether the respondent was married or had a life partner or other (i.e., divorced, separated, widowed, or never married). Living arrangement was a binary measure indicating whether the respondent lived alone or not.

Functional limitations were measured by the participant's score on a lower body functional assessment (Guralnik et al. 1994) and their grip strength. The comorbidity scales takes into account the extent to which the chronic condition limits daily activities. Here, we as the 
Disablement Process Model delineates, conceptualize functional limitations as distinct from disability or limitations in daily activities (Verbrugge and Jette 1994). Lower body function was a composite score of the three tasks that comprise the Short Physical Performance Battery: chair stands, 4-meter walk, and a balance test. Scores on the Short Physical Performance Battery can range from 0 to 12 , with higher scores indicating better lower body function. We also assessed the respondent's grip strength of their dominant hand using a handgrip dynamometer. Respondents were asked to grip the dynamometer as hard as they could three times and we used the average grip strength in pounds.

The psychosocial factors included depressive symptomatology (Radloff 1977), social support (Sherbourne and Stewart 1991), and personal mastery (Pearlin and Schooler 1978), which were all treated as continuous measures. The assessment of depressive symptomatology was conducted with the Center for Epidemiologic Studies Depression Scale, a multidimensional screening instrument for mood disorders and acute depressive symptoms experienced over a 7-day period. We asked respondents to indicate how often they had felt in response to 20 statements during the past week: rarely ( $<1$ day), sometimes (1-2 days), occasionally (3-4 days), or most times (5-7 days). All items except four were stated in the negative and were reversed coded. Scores on the depression measure can range from 0 to 60 , with higher scores indicating more depressive symptomatology. Social support was measured using the Medical Outcomes Study Social Support scale, which measures strength of perceived social support available. It consists of 19 items and asks how often each of the kinds of support is available if needed. Response options included none of the time, a little of the time, some of the time, most of the time, and all of the time. Scores on the social support measure can range from 19 to 95 , with higher scores indicating greater support. The personal mastery scale measures generalized expectations about a person's sense of control and consists of seven items, with responses on a four point Likert scale $(1=$ strongly disagree, 2 = disagree somewhat, $3=$ agree somewhat, and $4=$ strongly agree). All items except two were stated in the negative, which we reverse coded. Scores on the personal mastery measure can range from 7 to 28 , with higher scores indicating lower personal mastery.

\section{Analyses}

Descriptive analyses examined sample socio-demographic characteristics, specific condition prevalence, the most common conditions reported as "quite a bit limiting," and the sample distribution on the comorbidity scale. Condition prevalence, identification of the most common limiting conditions, and the comorbidity scale distribution data were weighted using weights derived from the tribal enrollment data to account for our sampling stratification by age. To assess correlates of comorbidity, we used analysis of variance and regression models to assess the significance of unadjusted associations between the independent variables and the comorbidity scale. A Poisson regression model was fit for the comorbidity scale with independent variables that were significantly associated at the bivariate level at the $p \leq 0.05$ level. We estimated a Poisson regression model because the response variable was integer valued and highly skewed. There was a substantial amount of missing data for the regression especially on the psychosocial factors so we performed multiple imputation. This approach does not estimate missing values with an artificial value. Rather, it draws values randomly from the values that do exist for each variable. We then combined the results of the multiple imputations to generate the results presented. All analyses were performed using SAS software package version 9.2 (SAS Institute 2004).

\section{Results}

Table 1 shows percentages and frequencies of the study sample socio-demographics for those who had completed data for the comorbidity scale. The mean age of study participants 
was 70.7 years. The sample was primarily female $(65 \%)$, with $45 \%$ who were married or with a life partner and $28 \%$ lived alone. With respect to socioeconomic status, $31 \%$ had graduated from high school or had earned a General Educational Development credential and $63 \%$ reported an annual household income of less than $\$ 25,000$.

Eleven percent of the study sample reported having none of the 32 chronic conditions (data not shown). Table 2 shows the percentages and frequencies of the most prevalent conditions contrasted with findings from the two other studies on comorbidity and American Indians (Chapleski et al. 1997;John et al. 2003) and national prevalence statistics (Desai et al. 2001; Pleis and Lucas 2009; Schoenborn and Heyman 2009). The national statistics are from the National Health Interview Survey based on persons aged 55 years or older for hypertension, diabetes, vision loss, and hearing loss; aged 65 years or older for arthritis and back pain; and aged 70 years or older for cataracts. In our sample, the most prevalent conditions were hypertension, arthritis, and diabetes. Compared to the two previously published studies with older American Indian samples, we found higher rates of hypertension and diabetes but were unable to compare back pain, cataracts, and broken bone(s) since these studies did not collect information on these conditions. Compared to national statistics, our sample's prevalence rates of hypertension, diabetes, back pain, vision loss were higher but we were unable to compare broken bone(s) since we did locate national statistics by age for this condition. It is worth noting that our sample's arthritis prevalence was similar (44\% vs. $48 \%$ ) to the national statistics, which were based on persons aged 65 years or older. Also, our sample's cataracts prevalence was similar (25\% vs. $26 \%)$ to the national statistic, which was for persons age 70 years or older.

Figure 1 shows the most common conditions based on counts reported as "quite a bit limiting" in performing daily activities. Back pain, arthritis, and chronic pain syndrome were the three reported by the greatest number of respondents as "quite a bit limiting."

The sample distribution on the comorbidity scale is displayed in Fig. 2. Thirty-three percent $(n=143)$ of the study sample had a value of zero on the scale. Of the $33 \%$, some may have indicated having one or more of the 32 conditions but they reported no limitations in their ability to do their daily activities. The mean score on the scale was 5.8 with a standard deviation of 7.8 and a range of $0-46$.

Results from the examination of unadjusted associations between the independent variables and the comorbidity scale (not shown), suggested that gender, marital status, and living arrangements were not associated with scores on the comorbidity scale. Thus, the regression results presented in Table 3 did not include these three socio-demographic characteristics. The regression analysis revealed that older age was associated with higher scores on the comorbidity scale while income and education were not. Our measures of functional limitations were associated with comorbidity. Specifically, better lower body strength and stronger grip strength were associated with lower comorbidity scale scores. Among the psychosocial factors, depressive symptomatology and personal mastery were associated with comorbidity but social support was not. That is, more depressive symptomatology and lower personal mastery were associated with higher comorbidity scale scores.

\section{Discussion}

The data presented here provide a broad overview of comorbidity with a unique populationbased sample of older American Indians. We examined the most prevalent chronic conditions, described comorbidity, and identified socio-demographic, functional limitations, and psychosocial correlates with comorbidity among a community sample of older American Indians. Our results indicated that our sample of American Indians experience 
higher rates of hypertension, diabetes, back pain, and vision loss compared to the general U.S. older adult population. Also, our sample of persons aged 55 years or older had approximately the same cataracts prevalence as been reported for the general U.S. adult population aged 70 years or older (Pleis and Lucas 2009) and similar arthritis prevalence as been reported for the general U.S. adult population aged 65 years or older (Desai et al. 2001). Compared to the two published studies with older American Indians (e.g., Chapleski et al. 1997; John et al. 2003), we found higher rates of hypertension and diabetes.

We used a survey-based measure of comorbidity that assessed the burden of 32 chronic conditions. Our comorbidity scale revealed that slightly less than a third of our sample did not experience comorbidity. Correlates of higher comorbidity scores included older age, poorer physical functioning, more depressive symptomatology, and lower personal mastery. There has been minimal to no research examining psychosocial correlates with comorbidity (Gijsen et al. 2001). Although there is a recognized link between depression and comorbidity, it has not been well-studied (O'Brien 2006). To our knowledge, this is the first study that has examined psychosocial correlates of comorbidity with American Indians.

This study has several limitations. First, the data are cross-sectional. Older adults experience health and associated severity from specific conditions and particular combinations of conditions over time. Our findings reflect chronic conditions and significant correlates of comorbidity at the time of the interview, so we are unable to capture these dynamic changes or determine causality. It is important to point out that particularly with our measures of functional limitations and psychosocial factors, the direction of the relationship with comorbidity can be a two-way street. For instance, while physical functioning has been most often theorized and examined as an outcome of comorbidity (Gijsen et al. 2001; Verbrugge and Jette 1994), recent discussions of comorbidity point out that disability contributes to or exacerbates chronic diseases (Fried et al. 2004). Second, the presence of chronic conditions is based on self-reports where medical chart confirmation of medical diagnosis is considered the gold standard. However, research has shown that there is generally good agreement between self-report of diagnosis and physician diagnosed for older adults (Bombard et al. 2005; Martin et al. 2000). Also of note, the American Indians who participated were all from the same tribe. Tremendous variations exist between the people known collectively as American Indians. As of August 2009, there were 564 federally recognized tribal entities (Bureau of Indian Affairs 2009) who maintain their own unique culture and traditions. Data have also shown that health status among American Indians varies by tribe and by region (Indian Health Service 2002; Rith-Najarian et al. 2002). Future research should examine other tribes besides the one that participated in this study.

Despite these limitations, we believe this research helps address our limited understanding of comorbidity for aging American Indians. Older American Indians are among the fastest growing populations in the United States with an estimated 1,319,00 who will be aged 55 years or older by 2020 (U.S. Census Bureau 2008). Although medical advances have increased life expectancy, morbidity and mortality statistics suggest that the health of older American Indians lags behind the majority population (Indian Health Service 2002). According to Indian Health Service data, life expectancy increased from 64 years in 1972/74 to 71 years in 1994/96 (Indian Health Service 2000). Yet, the life expectancy of American Indians today is still less than their White counterparts for males (67 vs. 75 years) and females (74 vs. 80 years) (Bramley et al. 2005). These data and our results speak to the need for ensuring older American Indians have access to chronic disease prevention, health promotion, and chronic disease management opportunities. Targeted efforts to prevent the onset of these conditions and effective management for those who have the conditions would have a positive effect on the aging experience for American Indians. 


\section{Acknowledgments}

This research was sponsored by the National Institute on Aging (AG022336). The authors would like thank Dr. Gerry Hobbs and Lili Dong for their assistance in the statistical analyses. The authors would also like to thank Dr. Lori Jervis and the two anonymous reviewers for their comments on earlier versions of the manuscript.

\section{References}

Anderson, G. Testimony before the Subcommittee on Heath of the House Committee on Ways and Means, Hearing on Promoting Disease Management in Medicare; 16 April 2002; 2002.

Bombard JM, Powell KE, Martin LM, Helmick CG, Wilson WH. Validity and reliability of selfreported arthritis: Georgia Senior Centers, 2000-2001. American Journal of Preventive Medicine. 2005; 28:251-258. [PubMed: 15766612]

Bramley D, Hebert P, Tuzzio L, Chassin M. Disparities in Indigenous health: A cross-country comparison between New Zealand and the United States. American Journal of Public Health. 2005; 95:844-850. [PubMed: 15855464]

Bureau of Indian Affairs. Indian entities recognized and eligible to receive services from the United States Bureau of Indian Affairs. Federal Register. 2009; 74:40218-40223.

Chapleski EE, Lichtenberg PA, Dwyer JW, Youngblade LM, Tsai PF. Morbididty and comorbidity among Great Lakes American Indians: Predictors of functional ability. The Gerontologist. 1997; 37:588-597. [PubMed: 9343909]

Denny CH, Holtzman D, Goins RT, Croft JB. Health behavior and health status disparities of American Indian and Alaska Native Elders: Findings from the behavioral risk factor surveillance system, 2001 and 2002. American Journal of Public Health. 2005; 95:825-827. [PubMed: $15855458]$

Desai, M.; Pratt, LA.; Lentzner, H.; Robinson, KN. Aging Trends. Vol. 2. Hyattsville. MD: National Center for Health Statistics; 2001. Trends in vision and hearing among older Americans.

Fillenbaum GG, Pieper CF, Cohen HJ, Cornoni-Huntley JC, Guralnik JM. Comorbidity of five chronic health conditions in elderly community residents: Determinants and impact on mortality. Journal of Gerontology. 2000; 55:M84-M89.

Fried LP, Bandeen-Roche K, Kasper JD, Guralnik JM. Association of comorbidity with disability in older women: The women's health and aging study. Journal of Clinical Epidemiology. 1999; 52:2737. [PubMed: 9973071]

Fried LP, Ferrucci L, Darer J, Williamson JD, Anderson G. Untangling the concepts of disability, frailty, and comorbidity: Implications for improved targeting and care. Journal of Gerontology. 2004; 59:M255-M263.

Gijsen R, Hoeymans N, Schellevis FG, Ruwaard D, Satariano WA, van den Bos GAM. Causes and consequences of comorbidity: A review. Journal of Clinical Epidemiology. 2001; 54:661-674. [PubMed: 11438406]

Guralnik, JM.; LaCroix, AZ.; Everett, DF. Aging in the eighties: The prevalence of comorbidity and its association with disability (Advance Data from Vital and Health Statistics). Vol. 170. Hyattsville, MD: National Center for Health Statistics; 1989.

Guralnik JM, Simonsick EM, Ferrucci L, Glynn RJ, Berkman LF, Blazer DG, et al. A short physical performance battery assessing lower extremity function: Association with self-reported disability and prediction of mortality and nursing home admission. Journal of Gerontology. 1994; 49:M85M94. [PubMed: 8126356]

Harboun M, Dorenlot P, Cohen N, Steinhagen-Thiessen E, Ankri J. Impact of hip fracture, heart failure and weight loss on the risk of institutionalization of community-dwelling patients with dementia. International Journal of Geriatric Psychiatry. 2008; 23:1245-1252. [PubMed: 18508392]

Hayward MD, Heron M. Racial inequality in active life among adult Americans. Demography. 1999; 36:77-91. [PubMed: 10036594]

Howard BV, Lee ET, Cowan LD, Devereux RB, Galloway JM, Go OT, et al. Rising tide of cardiovascular disease in American Indians. The Strong Heart Study. Circulation. 1999; 99:23892395. [PubMed: 10318659] 
Incalzi RA, Capparella O, Gemma A, Landi F, Bruno E, Di Meo F, et al. The interaction between age and comorbidity contributes to predicting the mortality of geriatric patients in the acute-care hospital. Journal of Internal Medicine. 1997; 242:291-298. [PubMed: 9366807]

Indian Health Service. Life expectancy. Data years: 1994-96. Rockville. MD: U.S. Department of Health and Human Services; 2000.

Indian Health Service. Trends in Indian health, 2000-2001. Rockville. MD: U.S. Department of Health and Human Services; 2002.

Inouye SK, Robison JT, Froehlich TE, Richardson ED. The time and change test: A simple screening test for dementia. Journal of Gerontology. 1998; 53:M281-M286.

John R, Kerby DS, Hennessy CH. Patterns and impact of comorbidity and multimorbidity among community-resident American Indian elders. The Gerontologist. 2003; 43:649-660. [PubMed: 14570961]

Marengoni A, Rizzuto D, Wang H, Winblad B, Fratiglioni L. Patterns of chronic multimorbidity in the elderly population. Journal of the American Geriatrics Society. 2009; 57:225-230. [PubMed: 19207138]

Martin LM, Leff M, Calonge N, Garrett C, Nelson DE. Validation of self-reported chronic conditions and health services in a managed care population. American Journal of Preventive Medicine. 2000; 18:215-218. [PubMed: 10722987]

McGee D, Cooper R, Lioa Y, Durazo-Arvizu R. Patterns of comorbidity and mortality risk in blacks and whites. Annals of Epidemiology. 1996; 6:381-385. [PubMed: 8915468]

O'Brien JT. Depression and comorbidity. The American Journal of Geriatric Psychiatry. 2006; 4:187190.

Paez KA, Zhao L, Hwang W. Rising out-of-pocket spending for chronic conditions: A 10 year trend. Health Affairs. 2009; 28:15-25. [PubMed: 19124848]

Pearlin LI, Schooler C. The structure of coping. Journal of Health and Social Behavior. 1978; 19:2-21. [PubMed: 649936]

Pleis, JR.; Lucas, JW. Vital Health Statistics. Vol. 10. Hyattsville, MD: National Center for Health Statistics; 2009. Summary health statistics for U.S. adults: National Health Interview Survey, 2007.

Radloff LS. The CES-D scale: A self-report depression scale for research in the general population. Applied Psychological Measures. 1977; 1:385-401.

Rigler SK, Studenski S, Wallace D, Reker DM, Duncan PW. Co-morbidity adjustment for functional outcomes in community-dwelling older adults. Clinical Rehabilitation. 2002; 16:420-428. [PubMed: 12061477]

Rith-Najarian SJ, Gohdes DM, Shields R, Skipper B, Moore KR, Tolbert B, et al. Regional variation in cardiovascular disease risk factors among American Indians and Alaska Natives with diabetes. Diabetes Care. 2002; 25:279-283. [PubMed: 11815496]

Rozzini R, Frisoni GB, Ferrucci L, Barbisoni P, Sabatini T, Ranieri P, et al. Geriatric index of comorbidity: Validation and comparison with other measures of comorbidity. Age and Aging. 2002; 31:277-285.

SAS Institute. SAS/STAT user's guide, version 9.1. Vol. 1-7. Cary, NC: Author; 2004.

Schoenborn CA, Heyman KM. Health characteristics of adults aged 55 years and over: United States, 2004-2007. National Health Statistics Reports 16. 2009

Sherbourne CD, Stewart AL. The MOS social support survey. Social Science \& Medicine. 1991; 132:705-714. [PubMed: 2035047]

Sievers ML, Bennett PH, Nelson RG. Effect of glycemia on mortality in Pima Indians with type 2 diabetes. Diabetes. 1999; 48:896-902. [PubMed: 10102709]

Smith GE, Kokmen E, O'Brien PC. Risk factors for nursing home placement in a population-based dementia cohort. Journal of the American Geriatrics Society. 2000; 48:519-525. [PubMed: 10811545]

Starfield B, Lemke KW, Herbert R, Pavlovich WD, Anderson G. Comorbidity and the use of primary care and specialist care in the elderly. Annals of Family Medicine. 2005; 3:215-222. [PubMed: 15928224] 
Stewart AL, Greenfield S, Hays RD, Wells K, Rogers WH, Berry SD, et al. Functional status and wellbeing of patients with chronic conditions. Journal of the American Medical Association. 1989; 262:907-913. [PubMed: 2754790]

U.S. Census Bureau. The American Indian and Alaska Native population 2000: Census 2000 Brief. Washington DC: 2002.

U.S. Census Bureau. Statistical abstract of the United States: 2008. Washington, DC: 2008. Projections of the American Indian and Alaska Native alone or in combination population by age and sex for the United States: 2010 to 2050.

Verbrugge LM, Jette AM. The disablement process. Social Science \& Medicine. 1994; 38:1-14. [PubMed: 8146699]

Verbrugge LM, Lepkowksi JM, Imanaka Y. Comorbidity and its impact on disability. The Milbank Quarterly. 1990; 67:450-484. [PubMed: 2534562]

Verbrugge LM, Gates D, Ike RW. Risk factors for disability among U.S. adults with arthritis. Journal of Clinical Epidemiology. 1991; 44:167-182. [PubMed: 1825325]

Wolff JL, Starfield B, Anderson G. Prevalence, expenditures, and complications of multiple chronic conditions in the elderly. Archives of Internal Medicine. 2002; 162:2269-2276. [PubMed: 12418941]

Wu, SY.; Green, A. Projection of chronic illness prevalence and cost inflation. Washington, DC: RAND Health; 2000.

Yancik R, Ershler W, Satariano W, Hazzard W, Cohen HJ, Ferrucci L. Report of the National Institute on Aging Task Force on Comorbidity. Journal of Gerontology. 2007; 62:M275-M280. 


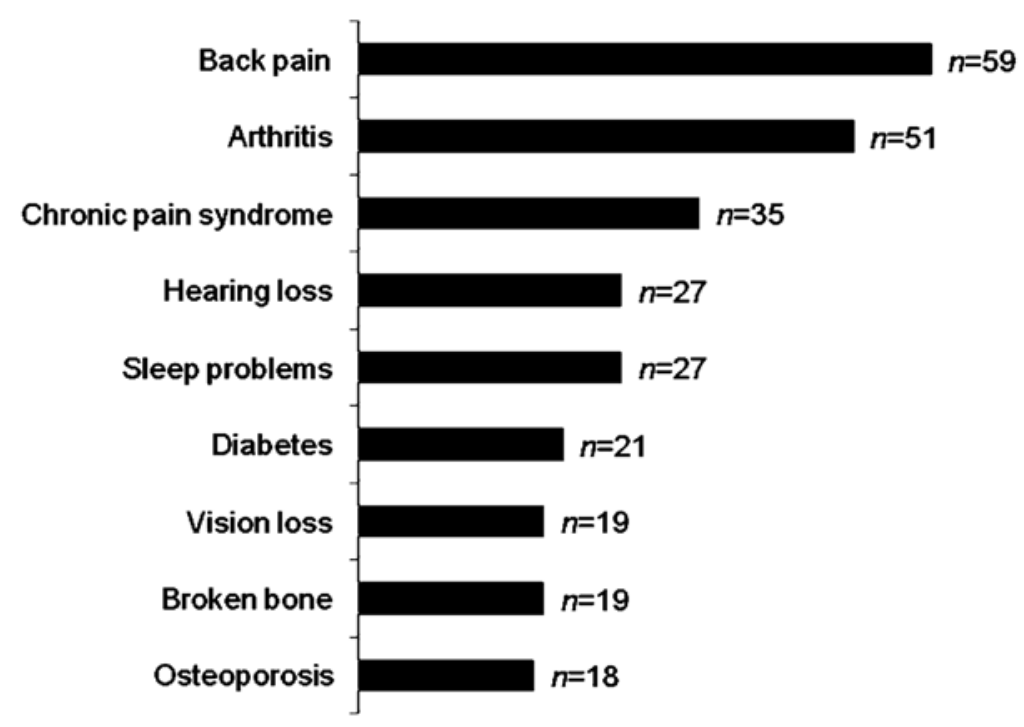

Fig. 1.

Most common conditions reported to be "quite a bit" limiting 


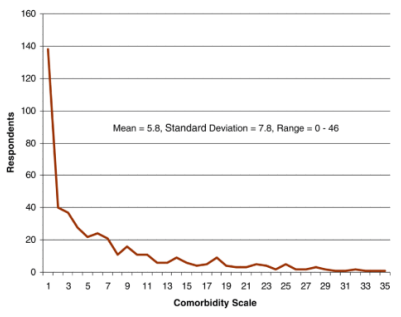

Fig. 2.

Study sample distribution on comorbidity scale 


\section{Table 1}

Study Sample Characteristics ( $n=446)$

\begin{tabular}{|c|c|c|}
\hline & $\%(\mathbf{n})$ & Mean \\
\hline Age, in years & & 70.7 \\
\hline $55-64$ & $30(133)$ & \\
\hline $65-74$ & $39(173)$ & \\
\hline$\geq 75$ & $31(140)$ & \\
\hline Female & 65 (289) & \\
\hline \multicolumn{3}{|l|}{ Marital Status } \\
\hline Married or life partner & 45 (198) & \\
\hline Divorced or separated & $17(76)$ & \\
\hline Widowed & $34(152)$ & \\
\hline Never married & $4(17)$ & \\
\hline \multicolumn{3}{|l|}{ Living Arrangements } \\
\hline Lives alone & $28(126)$ & \\
\hline Lives with 1 person & 44 (196) & \\
\hline Lives with $\geq 2$ persons & $28(121)$ & \\
\hline \multicolumn{3}{|l|}{ Educational Attainment } \\
\hline $1-11$ years & $41(181)$ & \\
\hline High school grad/GED & 31 (137) & \\
\hline College graduate or beyond & $28(126)$ & \\
\hline \multicolumn{3}{|l|}{ Annual Household Income } \\
\hline$\leq \$ 9,999$ & $12(39)$ & \\
\hline$\$ 10 \mathrm{k}-\$ 14,999$ & $17(55)$ & \\
\hline$\$ 15 \mathrm{k}-\$ 19,999$ & $21(67)$ & \\
\hline$\$ 20 \mathrm{k}-\$ 24,999$ & $13(42)$ & \\
\hline$\$ 25 \mathrm{k}-\$ 34,999$ & $17(55)$ & \\
\hline$\$ 35 \mathrm{k}-\$ 49,999$ & $9(30)$ & \\
\hline$\geq \$ 50 \mathrm{k}$ & $11(36)$ & \\
\hline
\end{tabular}

GED $=$ General Educational Development 
Table 2

Comparison of Native Elder Care Study Sample with Other Samples by Most Prevalent Chronic Conditions

\begin{tabular}{lllll}
\hline & Native Elder Care Study $\%$ & Chapleski et al. $\mathbf{1 9 9 7} \%$ & John et al. 2003 \% & National statistics \% \\
\hline Hypertension & 58 & 43 & 37 & $47^{a}$ \\
Arthritis & 44 & 61 & 50 & $48^{b}$ \\
Diabetes & 42 & 32 & 29 & $16^{a}$ \\
Back pain & 37 & NA & NA & $29^{b}$ \\
Vision loss & 31 & 29 & 53 & $14^{a}$ \\
Cataracts & 25 & NA & NA & $26^{c}$ \\
Hearing loss & 26 & 30 & 46 & $32^{a}$ \\
Broken bone(s) & 24 & NA & NA & NA \\
\hline
\end{tabular}

$\mathrm{NA}=$ not available

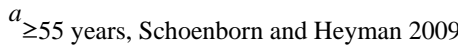

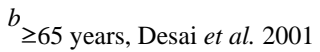

$c_{\geq 70 \text { years, Pleis and Lucas } 2009}$ 
Table 3

Poisson Regression Results Assessing Correlates of Comorbidity ( $n=446$ )

\begin{tabular}{lccc}
\hline & Parameter estimate & 95\% confidence intervals \\
\hline Socio-demographics & 0.076 & 0.009 & 0.142 \\
Older age & -0.022 & -0.068 & 0.023 \\
Higher income & 0.047 & -0.021 & 0.116 \\
$\quad$ Higher educational attainment & & & \\
Functional limitations & -0.078 & -0.097 & -0.059 \\
$\quad$ Better lower body function & -0.004 & -0.007 & -0.002 \\
$\quad$ Stronger grip strength & & & \\
Psychosocial factors & 0.018 & 0.012 & 0.024 \\
$\quad$ More depressive symptomatology & -0.002 & -0.006 & 0.002 \\
$\quad$ More social support & 0.020 & 0.009 & 0.031 \\
\hline Lower personal mastery & & & \\
\hline
\end{tabular}

